\title{
Prostat Kanseri ve Kemik Metastazı olan Bir Hastada Bifosfonat ile İlgili Çene Osteonekrozu: Bir Olgu Sunumu
}

\author{
Jaw Osteonecrosis Related to Bisphosphonate in A Patient with \\ Prostate Cancer and Bone Metastasis: A Case Report
}

Güldane Magat, Duygu Azman,

Necmettin Erbakan Üniversitesi Diş Hekimliği Fakültesi, Konya, Türkiye

Özet: Prostat kanseri ile ilişkili kemik metastazlarının üstesinden gelmek için intravenöz (IV) zoledronik asit ile tedavi edilmiş 80 yaşında bir erkek hastada maksillada nadir görülen bir osteonekroz olgusunu sunmayı amaçladık. 80 yaşındaki bir erkek hasta kliniğimize sol maksillasında ağrı şikâyeti ile başvurdu. Medikal hikâyesinde 2006 yılında iki taraflı Orşidektomi operasyonu geçirmiş kemik metastazlı prostat kanseri olduğu öğrenildi. Hasta kemoterapi almıştır ve daha sonra iki yıl öncesinde de IV zoledrononik asit ile bifosfonat tedavisi almıştır. Hastanın 1 yıl önce ağrıdan şikâyet ettiği bölgesinden diş çekimi yapıldığı öğrenilmiştir. Hastanın intraoral muayenesinde sol üst kaninden sol dişsiz posterior maksillaya kadar olan bölgede nekrotik kemik varlığı tespit edildi. Panoramik radyografta, ilgili bölgede radyolüsent alan gözlendi. Daha fazla inceleme için, konik 1şınlı bilgisayarlı tomografi (KIBT) alındı ve sol üst maksiller bölgede sekestr ve osteolizis varlığı tespit edildi. Spesifik olmayan, yumuşak doku yoğunluğunda artmış sol maksiller sinüzit tespit edildi. Medikal hikâye, klinik ve KIBT tarama incelemesi göz önüne alındığında, hastaya evre 3 osteonekroz tanısı kondu. Ağız, Diş ve Çene Cerrahisi bölümünde nekroz olan bölgesinin debridmanı yapılmış olup, sonrasında Protetik Diş Tedavisi bölümünde ilgili bölgenin protetik rehabilitasyonu sağlanmıştır. Bu vaka Ağız, Diş ve Çene Radyolojisi uzmanları, Ağız, Diş ve Çene Cerrahisi uzmanları ile Kulak Burun Boğaz uzmanlarının çene osteonekrozu tanısında ve tedavisinde önemli rolü olduğunu vurgulamakta ve bu durumun değişken belirti ve bulgularını ortaya koymanın farkındalığına ihtiyaç duyulduğunu göstermektedir.

Anahtar Kelimeler: Prostat kanseri; osteonekroz; maxilla

\begin{abstract}
We aimed to present a rare case of osteonecrosis in the maxilla in an 80-year-old male patient treated with intravenous (IV) zoledronic acid to overcome bone metastases associated with prostate cancer. An 80-year-old male patient was admitted to our clinic with pain in his left maxilla. In his medical history, it was learned that he had bilateral Orchidectomi operation in 2006 with bone metastasis. The patient received chemotherapy and then received bisphosphonate treatment with IV zoledrononic acid two years ago. It was learned that tooth extraction was made from the region where the patient complained of pain 1 year ago. In the intraoral examination of the patient, the presence of necrotic bone was detected in the region from the left upper canine to the posterior maxilla of the left toothless. On the panoramic radiograph, radiolucent area was observed in the relevant region. For further investigation, cone beam computed tomography (CBCT) was taken, and sequester and presence of osteolysis were detected in the upper left maxillary region. Nonspecific, soft tissue density increased left maxillary sinusitis was detected. Considering the medical history, clinical and CBCT examination, the patient was diagnosed with stage 3 osteonecrosis. In the Oral and Maxillofacial Surgery department, the necrosis region was debrided and afterwards, the prosthetic rehabilitation of the relevant region was provided in the Prosthetic Dentistry department. This case emphasizes that oral and dentomaxillofacial radiologists and maxillofacial surgeons, and otolaryngologists play an important role in the diagnosis and treatment of osteonecrosis of the jaw and show that there is a need for awareness that this situation reveals variable signs and symptoms.
\end{abstract}

Keywords: cancer; osteonecrosis; maxilla

ORCID ID of the authors: G.M. 0000-0003-4418-174X, D.A. 0000-0002-8321-7517 


\section{Giriş}

Bisfosfonatlar, pirofosfatların sentetik anologlarıdır. Kansere bağlı hiperkalsemi, solid tümörlerin kemik metastazları, Paget hastalığ 1 , Multipl Miyelom tedavisi, menopoz sonras1 osteoporozun tedavisi ve önlenmesinde kullanılır (1). Oral ve intravenöz (IV) olarak kullanılabilirler, ancak IV bifosfonatların toksik dozları kemikte oral bifosfonatlardan daha hizlı birikir. Bisfosfonatların en önemli yan etkileri çenelerdeki osteonekrozdur. Bifosfonatların kemik dokusundaki ana etkisi, kemiğin rezorpsiyonunu engelleyen ve dolayisiyla kandaki kalsiyum seviyesini azaltan osteoklastik aktivitenin inhibisyonudur. Ek olarak, kemik turn-over sistemi osteoklastik aktivitenin yokluğunda çökmekte ve yapının yıkım dengesi bozulmaktadır. Osteoklast ve osteoblastların uyarıcı etkileri osteoklastların inhibisyonu ile elimine edilir. Sonuç olarak, kemiğin organik matriksi onarılamadığı için mineral matriksi elastik hale gelmez, kırılganlaşır ve mikro çatlaklardan zarar görür. Kemiğin doğal yapısı avasküler hale gelir ve ölür. Nekroz gelişen kemik açığa çıkar veya fraktürler gelişir (2).

$\mathrm{Bu}$ çalıșma, prostat kanseri ile ilişkili kemik metastazlarını incelemek için IV zoledronik asit ile tedavi edilmiş 80 yaşında bir erkekte maksilla osteonekrozu olgusunu bildirmektedir. $\mathrm{Bu}$ durum osteonekrozun atipik olarak kemik metastazlarına benzer klinik bulgular ortaya çıkarma potansiyelini göstermektedir. Osteonekrozun bu şekilde ortaya çıkma ihtimalinin bilinmesi, ağız, diş ve çene radyolojisi, ağız, diş ve çene cerrahisi ve kulak burun boğaz alanında herkes için faydalı olacaktır.

\section{Olgu Sunumu}

80 yaşındaki erkek hasta kliniğimize sol maksillasındaki ağrı şikayeti ile başvurdu. Medikal hikayesinde, 2006 yılında bilateral Orşiektomi geçirdiği kemik metastazları ile prostat kanseri olduğunu ortaya koydu. Ameliyattan sonra, prostat kanseri tedavisi protokolüne göre kemoterapi almıștır: 6 siklus halinde 3 haftada bir prednizon ile sistemik steroid tedavisi ve bununla birlikte kombine edilen docetaxel. Birkaç y1l önce kardiyovasküler operasyon geçirdiği öğrenildi. İki yıl önce bir doz IV zoledronat 4 $\mathrm{mg}$ infüzyon ile hasta 2 ayda bir bifosfonat tedavisi görmüştür. 1 yıl önce ağrıdan şikayet ettiği bölgeden diş çekimi yapıldığı öğrenildi. Ekstraoral muayenede yüz konturunda fark edilebilir değişiklik olmadığı görüldü. İntraoral muayenede sinüs dahil sol üst kaninden sol dissiz posterior maksillaya kadar olan bölgede nekrotik kemik vardı (Resim 1). Sinüs açıklığında pürülan akıntı yoktu. Panoramik radyografta, ilgili bölgede radyolüsent alan gözlendi (Resim 2). Daha kapsamlı inceleme için, KIBT alındı ve sol üst maksiller bölgesinde sekestr ve osteolizis varlığ1 tespit edildi. Spesifik olmayan, yumuşak doku yoğunluğunda artmış sol maksiller sinüzit tespit edildi. Sol maksiller sinüsün ön, alt, medial ve lateral duvarlarında perforasyon vard1 (Resim 3-5). Medikal hikaye, klinik ve KIBT tarama incelemesi göz önüne alındığında, hastaya evre 3 BRONJ tanıs1 konuldu. Hastaya antibiyotik ve antifungal ilaçlarla kronik maksiller sinüzit tedavisi uyguland. Lokal anestezi altında sekestrotomi yapıldı.

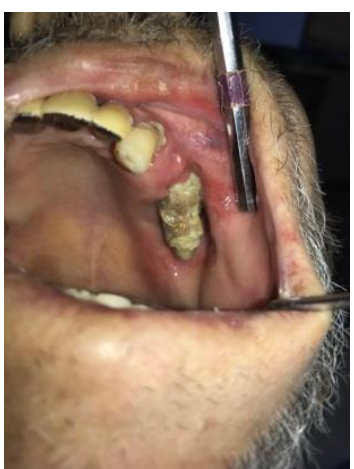

Resim 1. Sol maksiller dişsiz bölgede ağız ortamına açık nekrotik kemik varlığ 


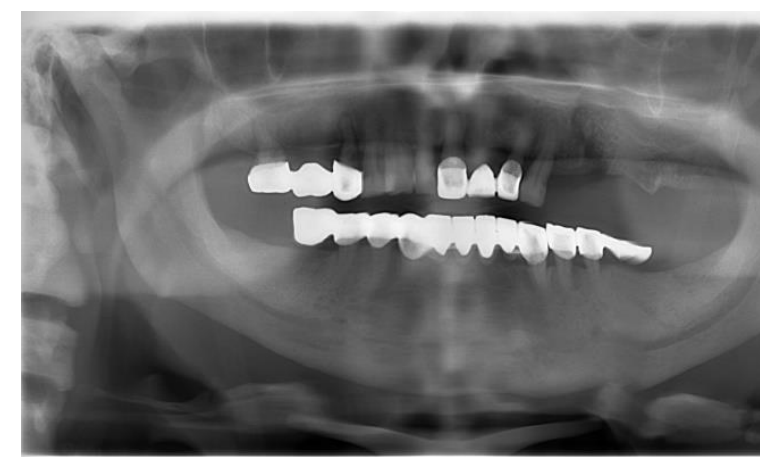

Resim 2. Hastanın panoramik radyografı

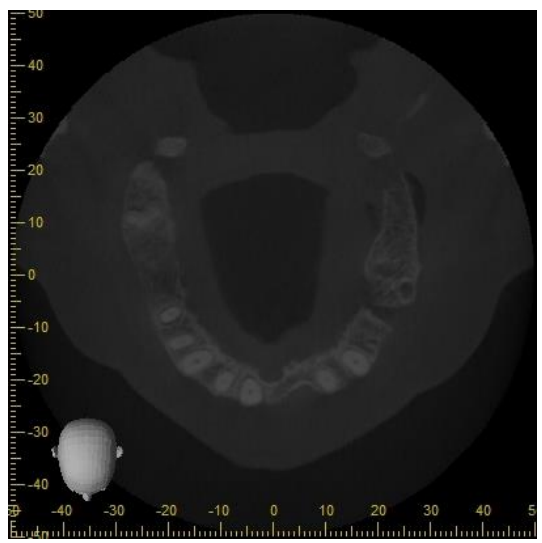

Resim 3. Konik ışınlı bilgisayarlı tomografinin aksiyel kesitindeki sekestr görüntüsü

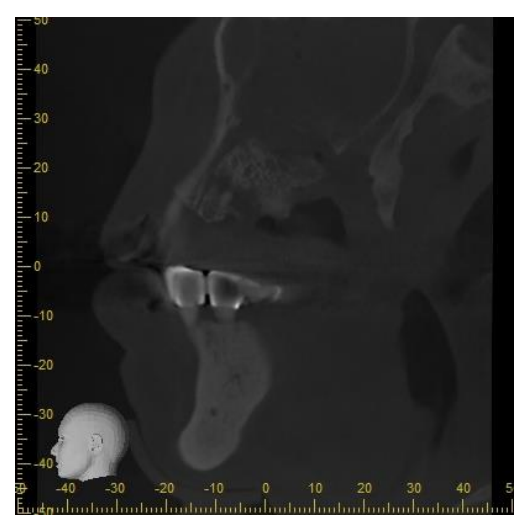

Resim 4. Konik ışınlı bilgisayarlı tomografinin sagittal kesitindeki sekestr görüntüsü

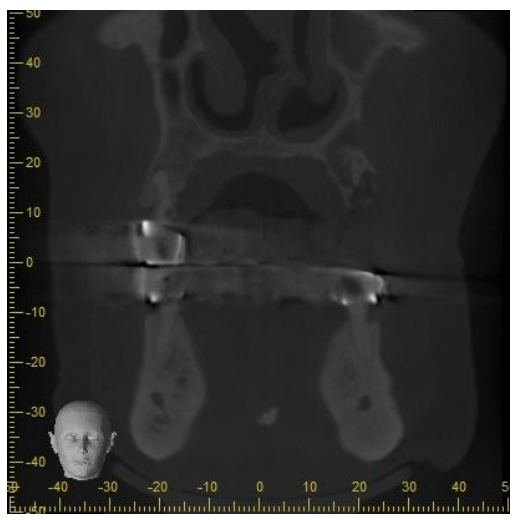

Resim 5. Konik ışınlı bilgisayarlı tomografinin koronal kesitindeki sekestr görüntüsü

\section{Tartışma}

Bisfosfonatlar, kemik matrisinde bol miktarda bulunan doğal bir kemik metabolizmas1 düzenleyicisi olan sentetik pirofosfatlardır (3). $\mathrm{Bu}$ bileşikler, osteoklastik öncüllerin farklılaşmasını engeller, osteoklast apoptozuna yol açar ve osteoblastik inhibitör faktörün osteoblastlardan ayrılmasını uyarır. Çok sayıda klinik çalışma bifosfonatların osteolitik kemik metastazı olan hastalarda patolojik kırık, kemik ağrısı, hiperkalsemi atakları ve radyoterapi ve cerrahi ihtiyacinı azaltabildiğini göstermiştir (4-5).

Zoledronik asit, kemik rezorpsiyonunun klinik öncesi testlerinde araştırılan en güçlü bisfosfonattır (6). Bununla birlikte, zoledronik asitin 36 aydan fazla kullanımında osteonekroz riski pamidronat kullanımından daha fazladır (7). Bizim vakamızda da hasta iki yıldır zoledronik asit kullanmakta idi.

Literatürde, hastaların çoğunda (\%69) osteonekroz gelişmeden önce ilgili bölgeden diş çekim öyküsü olduğu belirtilmiştir (8). Bizim vakamızda da diş çekimi hikayesi mevcut idi. $\mathrm{Bu}$ nedenle, çenenin osteonekrozunu önlemek için, bisfosfonat tedavisine başlamak üzere olan hastalarda tam bir ağız muayenesi gereklidir. 


\section{Sonuç}

Bifosfonatın osteoporoz ve kemik metastazl kanser tedavisi için uygun bulunmasıyla, sağlıç̣ılar, bifosfonat alan hastalarda yeni bir tip kemik nekrozu oluşma ihtimaline karşı dikkatli olmalıdır. $\mathrm{Bu}$ vaka oral ve maksillofasiyal radyologların, oral ve maksillofasiyal cerrahların ve kulak burun boğaz uzmanlarının, maksilla osteonekrozu

\section{KAYNAKLAR}

1. Onur Ö.D, Kurtuluş B, Çevik P, Bifosfonat Kullanan Hastalarda Oral Cerrahi Uygulamalarda Karşılaș1labilecek Sorunlar Ve Tedavisi Oral Complications And Treatments In Patients Receiving Bisphosphonates. Journal of Istanbul University Faculty of Dentistry. 2009;43:113-22.

2. Van Poznak C, Estilo C. Osteonecrosis of the jaw in cancer patients receiving IV bisphosphonates. Oncology (Williston Park). 2006;20:1053-62.

3. Russell RG, Bisaz S, Fleisch H, et al. Inorganic pyrophosphate in plasma, urine, and synovial fluid of patients with pyrophosphate arthropathy (chondrocalcinosis or pseudogout). Lancet. 1970;2:899-902.

4. Hortobagyi GN, Theriault RL, Porter L, et al. Efficacy of pamidronate in reducing skeletal complications in patients with breast cancer and lytic bone metastases. Protocol 19 Aredia Breast Cancer Study Group. $N$ Engl $J$ Med. 1996;335:1785-91.

5. Santini D, Vespasiani Gentilucci U, Vincenzi B, et al. The antineoplastic role of bisphosphonates: from basic research to clinical evidence. Ann Oncol. 2003;14:1468-76.

6. Michaelson MD, Smith MR. Bisphosphonates for treatment and prevention of bone metastases. $J$ Clin Oncol. 2005;23:8219-24.

7. Ficarra G, Beninati F, Rubino I, Vannucchi A, Longo G, Tonelli P, et al. Osteonecrosis of the jaws in periodontal patients with a history of bisphosphonates treatment. J Clin Periodontol. 2005;32:1123-8.

8. Van den Wyngaert T, Huizing MT, Vermorken JB. Bisphosphonates and osteonecrosis of the jaw: cause and effect or a post hoc fallacy? Ann Oncol. 2006;17:1197-204. tanısında ve tedavisinde önemli rolünü vurgulamaktadır ve bu durumun değişkenlik gösteren belirti ve semptomlarını gösteren farkındalık ihtiyacını göstermektedir. Önleyici önlemler bisfosfonatlarla yapilan tedaviden önce, sirasinda ve sonrasinda alınmalıdır. KIBT görüntüleme, maksilla ve mandibulanın kortikal ve trabeküler yapısındaki erken değişikliklerin üç boyutlu değerlendirilmesinde yardımcı olabilir. 